\title{
A novel type of subtilase from the psychrotolerant bacterium Pseudoalteromonas sp. SM9913: catalytic and structural properties of deseasin MCP-01 \\ Correspondence \\ Yuzhong Zhang \\ zhangyz@sdu.edu.cn \\ Received 14 January 2007 \\ Revised 11 March 2007 \\ Accepted 12 March 2007

\author{
Xiu-Lan Chen, Bin-Bin Xie, Jing-Tao Lu, Hai-Lun He and Yuzhong Zhang
} \\ The State Key Laboratory of Microbial Technology, Marine Biotechnology Research Center, Shandong University, Jinan 250100, China

\begin{abstract}
MCP-01, the main protease secreted by the deep-sea cold-adapted bacterium Pseudoalteromonas sp. SM9913, is a cold-adapted serine protease. Gene mcp01 encoding MCP-01 contains an ORF of 2508 bp encoding a protein of 835 amino acid residues with an $M_{r}$ of $87773 \mathrm{Da}$, which is a multidomain subtilase precursor. Mature MCP-01 purified from the culture of strain SM9913 with an $M_{r}$ of $65.84 \mathrm{kDa}$ is a multidomain protein composed of a catalytic domain, a linker, a P_proprotein domain and a polycystic kidney disease (PKD) domain. To the best of the authors' knowledge, no mature subtilase has been reported to date with this domain architecture. Phylogenetic analyses of subtilases showed that MCP-01 and 12 hypothetical proteins retrieved from public databases form a strongly supported group within the subtilase subfamily. These 13 proteins are predicted to share a similar domain architecture and represent a structurally novel group within the S8A subfamily. The substrate specificities of MCP-01 towards synthetic peptides differed from that of a typical S8A protease, subtilisin Carlsberg. Since most of this new subgroup of subtilases, including MCP-01 and the 12 MCP-01-like subtilases, are from deep-sea bacteria, they are termed deseasins. MCP-01 is the type example of a deseasin, since it is the only one that has been purified and characterized. In addition, the structural characteristics and catalytic properties of deseasin MCP-01 show that structurally and kinetically it is adapted to low temperatures.
\end{abstract}

\section{INTRODUCTION}

Serine proteases are an extensively studied type of protease and are grouped into 14 clans in the latest release of the MEROPS database (the peptidase database at http:// merops.sanger.ac.uk/) (Rawlings et al., 2006). Peptidase family S8, also known as the subtilisin or subtilase family, is the second-largest family of serine proteases. Peptidases in this family are all characterized by an Asp/His/Ser catalytic triad and an alpha/beta fold catalytic centre containing a seven-stranded parallel beta-sheet (Rawlings et al., 2006). Most subtilases are monodomain proteins, particularly as mature enzymes. Some members from Vibrio and its close relatives are mosaic proteins and possess a special

Abbreviations: FVR, $N$-benzoyl-Phe-Val-Arg- $p$-nitroanilide; AAPF, $N$ succinyl-Ala-Ala-Pro-Phe-p-nitroanilide; AAPL, $N$-succinyl-Ala-Ala-ProLeu-p-nitroanilide; AAV, N-succinyl-Ala-Ala-Val-p-nitroanilide; GGG, $N$ succinyl-Gly-Gly-Gly-p-nitroanilide; GGF, $\quad N$-succinyl-Gly-Gly-Phe- $p$ nitroanilide; PKD, polycystic kidney disease; TAIL PCR, thermal asymmetric interlaced PCR.

The GenBank/EMBL/DDBJ accession no. for the nucleotide sequence data reported in this study is DQ371965.

Supplementary data is available with the online version of this paper.
C-terminal domain required for secretion that is proteolytically removed upon extracellular activation (Rawlings \& Barrett, 2004). As at 12 January 2007, 1390 subtilases were included in the peptidase database (Rawlings et al., 2006). However, most of these are predicted proteins, derived from corresponding gene or cDNA sequences, the biochemical properties of which are hardly known.

Subtilases occur in archaea, bacteria, viruses, fungi, yeasts and higher eukaryotes. In bacteria, archaea and fungi, most of the subtilases are secreted and are probably involved in nutrition. Some subtilases have been applied in biotechnology. For example, subtilisin and proteinase $\mathrm{K}$ are used as reagents to make peptides from proteins, and subtilisin is an active agent in biological washing powders (Rawlings et al., 2006). With the discovery and characterization of novel kinds of subtilase, further applications in biotechnology may be found.

In recent years, there has been a growing interest in coldadapted enzymes, both as models in studies of thermal stability and the molecular adaptation of proteins, and as potential candidates for biotechnological applications (Georlette et al., 2004). To date, most of the psychrophilic 
proteases studied have been from bacteria isolated from Arctic and Antarctic locations. In contrast, psychrophiles and psychrophilic enzymes reported from deep-sea strains are poorly represented, probably because of the difficulties of sample collection and micro-organism cultivation. The deep sea (except near hydrothermal vents) is permanently cold, and many kinds of psychrophilic micro-organism live there. In addition to low temperature, deep-sea environments are characterized by high pressure, and high salt and low nutrient concentrations. Psychrophilic micro-organisms surviving under these extreme conditions must have a complex suite of morphological, physiological and metabolic adaptations. Accordingly, there is a greater chance of finding novel enzymes with unusual characteristics in deep-sea psychrophiles, and they may have special applications in biotechnology.

We isolated a cold-adapted bacterium Pseudoalteromonas sp. SM9913 from a deep-sea sediment at $1855 \mathrm{~m}$ depth that was shown to secrete proteases. The serine protease MCP01 is the main protease secreted by this strain (Chen et al., 2003a). This enzyme has been developed into a novel flavorzyme to improve the flavour of refrigerated meat ( $\mathrm{He}$ et al., 2004). In this article, the cloning, sequencing and analysis of the gene encoding protease MCP-01, as well as the evolutionary relationships among subtilase members, are described. The structure and biochemical properties of the purified MCP-01 were also studied. The results showed that MCP-01 is a novel type of subtilase with cold-adapted characteristics, termed a deseasin, belonging to subfamily S8A.

\section{METHODS}

Bacterial strains, plasmids, and growth conditions. Pseudoalteromonas sp. SM9913 was cultured at $12{ }^{\circ} \mathrm{C}$ in the medium previously described (Chen et al., 2003a). Escherichia coli DH5 $\alpha$ was grown at $37{ }^{\circ} \mathrm{C}$ on Luria-Bertani medium supplemented with ampicillin for the selection of transformants. Plasmid pGEM-T vector (Promega) was used for cloning and sequencing.

Purification of MCP-01. Protease MCP-01 produced by Pseudoalteromonas sp. SM9913 was purified from its culture supernatant by the procedure previously described (Chen et al., 2003a). Briefly, the culture supernatant was precipitated by adding $55 \%$ solid ammonium sulfate powder. The precipitate was dissolved in $50 \mathrm{mM}$ Tris/ $\mathrm{HCl}$ buffer ( $\mathrm{pH} 8.5)$ and dialysed against the same buffer. Then it was concentrated by PEG 20000 . The concentrated sample was then put on a column of Sephadex G100 which was eluted with $50 \mathrm{mM}$ Tris/ $\mathrm{HCl}$ buffer $(\mathrm{pH} 8.5)$ at a rate of $8 \mathrm{ml} \mathrm{h}^{-1}$. The eluate was collected in $3 \mathrm{ml}$ fractions. The purity of MCP-01 in each fraction was monitored by capillary electrophoresis, as described previously (Chen et al., 2003b). The fractions without any peak representing an impurity, as shown in Supplementary Fig. S1, were collected for use. All procedures were performed at $0-5{ }^{\circ} \mathrm{C}$.

$\mathbf{N}$-terminal amino acid sequence analysis of MCP-01 and its autolytic peptides. Since MCP-01 is susceptible to autolysis (Chen et al., 2002, 2003b), the purified MCP-01 was incubated at $35^{\circ} \mathrm{C}$ for $2 \mathrm{~h}$ to allow autolysis to take place. Then, MCP-01 and its autolytic peptides were separated by SDS-PAGE by the method of Laemmli
(1970) and transferred to Sequi-Blot PVDF membranes (Bio-Rad). Nterminal amino acid sequences of MCP-01 and the protein bands of its autolytic peptides were analysed by Edman degradation employing the Procise CLC sequencer (Applied Biosystems) at Shanghai GeneCore BioTechnologies.

Cloning of gene mcp01 encoding protease MCP-01. Genomic DNA of Pseudoalteromonas sp. SM9913 was extracted by the $\mathrm{NaCl} /$ cetyltrimethylammonium bromide (CTAB) method (Murray \& Thompson, 1980). Based on the N-terminal amino acid sequences of MCP-01 (SATNDPRF) and one autolytic peptide (AVDNDQNP), two primers were designed and synthesized. With the genomic DNA of Pseudoalteromonas sp. SM9913 as template, PCR amplification was performed by Taq DNA polymerase for 30 cycles consisting of $94{ }^{\circ} \mathrm{C}$ for $30 \mathrm{~s}, 50{ }^{\circ} \mathrm{C}$ for $1 \mathrm{~min}$ and $72{ }^{\circ} \mathrm{C}$ for $2 \mathrm{~min}$, and a $620 \mathrm{bp}$ product was amplified. Its sequence was determined by Shanghai Invitrogen Biotechnology. Three specific primers were designed based on its $5^{\prime}$ terminal sequence, three based on its $3^{\prime}$ terminal sequence, and two general primers were designed containing the protein initiation codon and the stop codon, respectively. Then, chromosome walking was used to amplify the neighbouring sequence of the 620 bp product by thermal asymmetric interlaced (TAIL) PCR (Liu \& Whittier, 1995). In this way, a $494 \mathrm{bp}$ upstream sequence and a $713 \mathrm{bp}$ downstream sequence of the $620 \mathrm{bp}$ product were amplified from the genomic DNA of Pseudoalteromonas sp. SM9913 and sequenced. Then, an 1827 bp sequence predicted to contain the ATG start codon of gene mcp01 was assembled. Based on the $3^{\prime}$ terminal sequence of this $1827 \mathrm{bp}$ fragment, new specific primers were designed and its neighbouring sequence was amplified by TAIL PCR from the genomic DNA. Then, an 849 bp downstream sequence of the 1827 bp fragment was amplified and sequenced. Through assembly, a 2676 bp sequence containing a $2508 \mathrm{bp}$ ORF that encodes gene mcp01 was obtained. Two primers were designed based on the $5^{\prime}$ and $3^{\prime}$ terminal sequences of this ORF, and then gene mcp01 was amplified from the genomic DNA of Pseudoalteromonas sp. SM9913 by PCR and sequenced. Its sequence was verified to correspond to that amplified by TAIL PCR.

Activity assay of protease MCP-01. The enzyme activity towards casein was determined as previously described (Chen et al., 2003a). Proteolytic activity with BSA or gelatin as the substrate was determined in $50 \mathrm{mM}$ Tris/HCl buffer ( $\mathrm{pH}$ 8.0) by the same method. Proteolytic activities towards synthetic substrates were determined in $50 \mathrm{mM}$ Tris/ $\mathrm{HCl}$ buffer (pH 9.0) by Peek's method (Peek et al., 1993). One unit of enzyme activity was defined as the amount of enzyme that catalysed the formation of one micromole of $p$-nitroaniline per minute.

Characterization of MCP-01. The optimum $\mathrm{pH}$ was determined using the method previously reported (Chen et al., 2003a). The temperature optimum was determined by monitoring activity over $10 \mathrm{~min}$ at optimum $\mathrm{pH}$ between 0 and $40^{\circ} \mathrm{C}$. The kinetic parameters of MCP- 01 were determined at 5 and $20^{\circ} \mathrm{C}$ by Lineweaver-Burk plots which were made by linear regression with initial rates determined between 0 and $1 \mathrm{mg} \mathrm{ml}^{-1} \mathrm{~N}$-succinyl-Ala-Ala-Pro-Leu- $p$-nitroanilide (AAPL). The activation energy $\left(E_{\mathrm{a}}\right)$ of the enzymic reaction was calculated by measuring the slope of the Arrhenius plot, which was made based on the $k_{\text {cat }}$ values at $0-20{ }^{\circ} \mathrm{C}$, employing the equation:

$\ln k_{\mathrm{cat}}=\ln \mathrm{A}-E_{\mathrm{a}} / \mathrm{R} T$

$k_{\text {cat }}$ values used in the Arrhenius plot were calculated based on the reaction rates measured at given temperatures. Thermodynamic activation parameters of catalysis of MCP-01 were calculated by the equations $\Delta G^{\#}=\Delta H^{\#}-T \Delta S^{\#} ; \quad \Delta H^{\#}=E_{\mathrm{a}}-\mathrm{R} T ; \quad$ and $\quad \Delta S^{\#}=2.303 \mathrm{R}\left(\log k_{\mathrm{cat}}-10.753\right.$ $\left.-\log T+E_{\mathrm{a}} / 2.303 \mathrm{R} T\right)$ (Kulakova et al., 1999).

Activity assay and characterization of subtilisin Carlsberg. Purified subtilisin Carlsberg (type III, lyophilized powder) was 
purchased from Sigma. As reported by the manufacturer, it had been purified by crystallization. We did not detect any other protein fragment by electrophoresis. A $1 \mathrm{mg} \mathrm{ml}^{-1}$ solution of subtilisin Carlsberg was prepared in $50 \mathrm{mM}$ Tris/ $\mathrm{HCl}$ buffer $(\mathrm{pH} \mathrm{10.0)}$. The enzyme was diluted in the same buffer for characterization experiments. The temperature optimum was determined by monitoring activity from 0 to $70{ }^{\circ} \mathrm{C}$ at $\mathrm{pH} 10.0$ with $1 \mathrm{mg} \mathrm{AAPL} \mathrm{ml}^{-1}$ as substrate and the enzyme concentration used was $0.1 \mu \mathrm{g} \mathrm{ml}^{-1}$ at 0 $30{ }^{\circ} \mathrm{C}$ and $0.05 \mu \mathrm{g} \mathrm{ml}^{-1}$ at $30-70{ }^{\circ} \mathrm{C}$. Kinetic parameters of subtilisin Carlsberg were determined at 5 and $20^{\circ} \mathrm{C}$ by Lineweaver-Burk plots which were made by linear regression with initial rates determined between 0 and $1 \mathrm{mg} \mathrm{AAPL} \mathrm{ml}{ }^{-1}$ and the enzyme concentration used was $0.1 \mu \mathrm{g} \mathrm{ml}^{-1} . E_{\mathrm{a}}, \Delta G^{\#}, \Delta H^{\#}$ and $\Delta S^{\#}$ were determined by the same methods and equations used for MCP-01.

Analytical procedures. The protein concentration of MCP-01 was determined by the Bradford method with BSA as standard (Bradford, 1976). The isoelectric point of MCP-01 was determined by the method of Huang \& Forsberg (1987). The molecular mass of the purified MCP-01 was determined by MALDI-TOF MS (Voyager DE Pro, Applied Biosystems) at Shanghai GeneCore BioTechnologies.

Domain architecture analysis and phylogenetic analysis. To search for sequences similar to MCP-01, the non-redundant databases at the NCBI (http://www.ncbi.nlm.nih.gov/) and the MEROPS database (release 7.60) (Rawlings et al., 2006) were searched using the BLAST service available at the respective websites with default parameters. Then, the domain architectures of the obtained sequences were analysed with the CD-search service (Marchler-Bauer et al., 2005) available at NCBI (http://www.ncbi.nlm.nih.gov/Structure/cdd/ cdd.shtml). Database CDD version 2.10 [with 12589 position-specific scoring matrices (PSSMs)] and default parameters were used. The representative sequences were aligned with CLUSTAL X 1.83 (Thompson et al., 1997) using the PAM matrix (Dayhoff et al., 1978). The resulting alignment was manually modified with the aid of BioEdit (Hall, 1999). Positions containing alignment gaps were removed before phylogenetic analyses to get a more reliable tree. The catalytic domain portion of the final alignment was used to construct a neighbour-joining consensus tree using MEGA 3.1 (Kumar et al., 2004). A PAM model and 1000 bootstrap replicates were used. Multiple independent analysis runs were performed with different seed numbers. The results showed that the seed number did not affect the topology of subtrees whose bootstrap support was greater than $40 \%$. Detailed information relating to the sequences used for constructing evolutionary trees is shown in Supplementary Table S1.

\section{RESULTS}

\section{Cloning and nucleotide sequence analysis of the gene encoding MCP-01}

Gene $m c p 01$, encoding protease MCP-01, was cloned by TAIL PCR and confirmed by reamplifying the gene from the genomic DNA of strain SM9913, as described in Methods. The ORF of gene mcp01 has $2508 \mathrm{bp}$ with an ATG start codon and a TAA stop codon. It encodes a protein of 835 amino acid residues with a calculated $M_{\mathrm{r}}$ of $87773 \mathrm{Da}$. The ORF was predicted to encode a typical signal peptide sequence by LipoP (Juncker et al., 2003) and signalP (Bendtsen et al., 2004). CD-search analysis of the deduced amino acid sequence of MCP-01 revealed that the gene encodes a modular enzyme consisting of seven regions: a signal sequence (M117 to A99), a subtilisin_N domain (I79 to A1), a protease catalytic region (D27 to S301), a long linker (G302 to T467), a P_proprotein domain (T468 to F546), a polycystic kidney disease (PKD) domain (P554 to V633) and a C-terminal sequence (S634 to E718). The BLASTP search showed that MCP-01 has higher identity to subtilases than to other serine proteases, and it has the same domain architecture as 12 other predicted proteases in public databases, which are from unnamed Alteromonadales bacterium TW-7 (gi119469818), Pseudoalteromonas haloplanktis TAC125 (gi76877026), Pseudoalteromonas tunicata D2 (gi88859101), Shewanella sp. ANA-3 (gi117921848), Shewanella oneidensis MR-1 (gi24372456), Shewanella denitrificans OS217 (gi91794442), Shewanella sp. MR-4 (gi113969067), Alteromonas macleodii 'deep ecotype' (gi88793375), Idiomarina loihiensis L2TR (gi561459272), Shewanella woodyi ATCC 51908 (gi118071172), Shewanella amazonensis SB2B (gi119773579) and Shewanella sp. strain PV-4 (gi78368142) (Fig. 1). The sequence similarities between these MCP-01-like sequences and MCP-01 are very high (identities $30-82 \%$ and similarities $48-93 \%$ ). Most of these predicted proteases have a sequence length of 818-844 aa, which is very similar to that of MCP-01 (835 aa). Two of the predicted proteases, gi119773579 and gi78368142, are significantly longer at 1151 and 1150 aa, respectively. Analysis of the domain architecture of these showed that both of them have two P_proprotein domains between the linker and the PKD domain, which leads to a longer sequence than that of other proteases of this type (Fig. 1).

\section{Phylogenetic analysis of MCP-01}

In order to group MCP-01 into a known family, MCP-01 was used as a query to search the MEROPS database with the BLAST tool available at the website. The top 100 retrieved sequences were from the subfamily S8A of serine proteases, indicating the probable membership of S8A of MCP-01. Of the 100 sequences, only 30 have been assigned to subgroups within S8A, and they are under 19 different MEROPS identification numbers (S08.001, S08.003, S08.004, S08. 005, S08.007, S08.009, S08.010, S08.012, S08.013, S08.021, S08.034, S08.037, S08.038, S08.050, S08.056, S08.098, S08.101, S08.105 and S08.115). The remaining 70 are members of S8A, but have not been assigned to any subgroup within S8A. In order to determine the evolutionary relationships between MCP-01 and the members of $\mathrm{S} 8 \mathrm{~A}$, a consensus neighbour-joining tree was constructed using the catalytic domain peptidase_S8. In the tree, MCP01 and the 12 MCP-01-like sequences form a monophyletic group (Fig. 1). The high bootstrap percentage, $99 \%$, and the long distance from the other sequences indicate that MCP01 and the MCP-01-like sequences are a new type of subtilase (Fig. 1). The domain architectures of proteases in the tree are shown to the right of Fig. 1. It is clearly shown that the domain architectures of MCP-01 and MCP-01-like proteases are different from those of other subtilases in S8A, which have no P_proprotein domain or PKD domain at the $\mathrm{C}$ terminus. We termed this new group deseasins. 


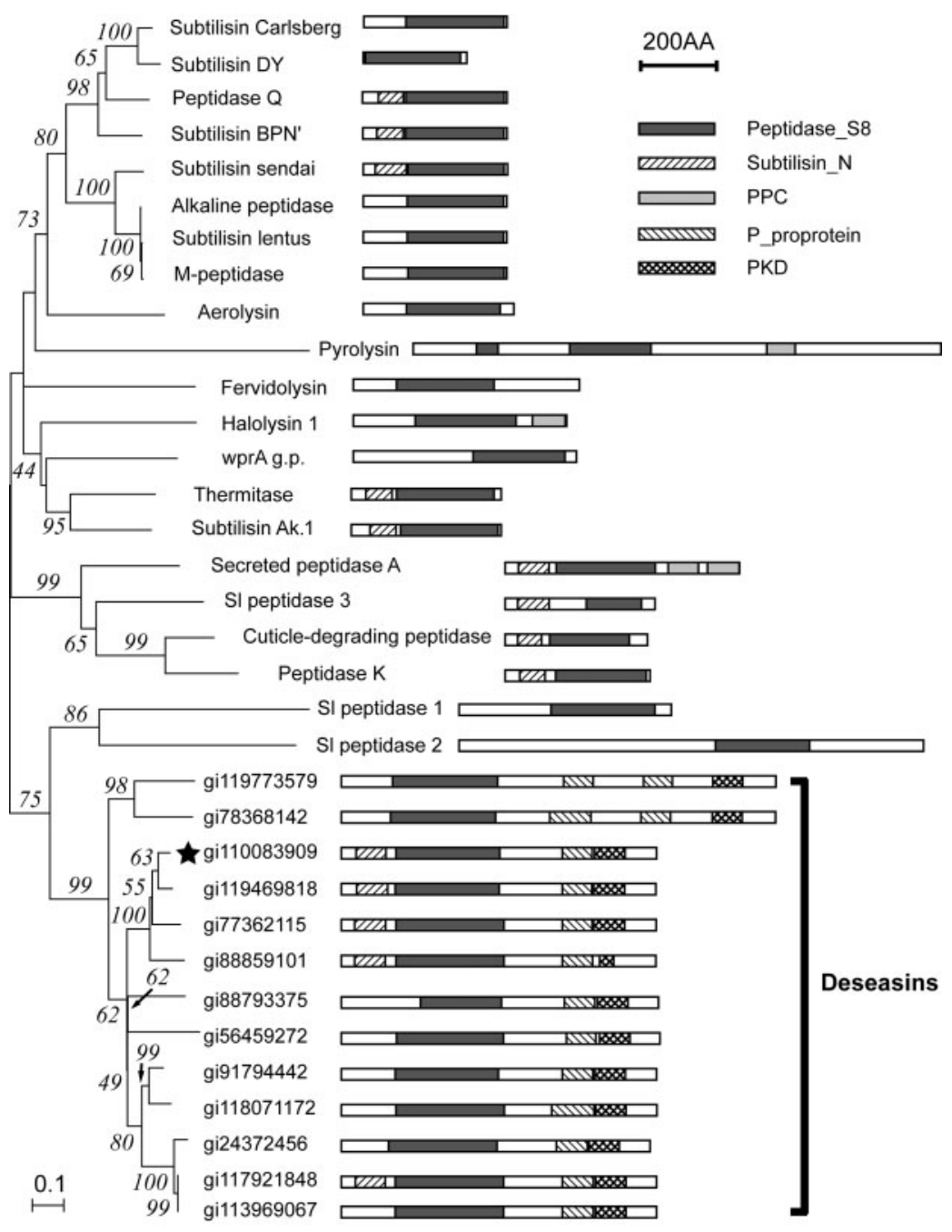

Fig. 1. Representative consensus neighbourjoining tree of the catalytic domain (left of figure), and schematic diagrams of the domain structure (right of figure) of MCP-01 and related sequences. The consensus tree of the catalytic domain (peptidase_S8) was constructed using MEGA 3.1 with PAM model. One thousand bootstrap replicates were used. Only bootstrap percentages $>40 \%$ are shown on the branches. The conserved domain architectures of the sequences were identified using the CD-search service available at $\mathrm{NCBI}$ (http://www.ncbi.nlm.nih.gov/Structure/cdd/ cdd.shtml). The conserved domains are: peptidase_S8, subtilase family, pfam00082; subtilisin_N, subtilisin N-terminal region, pfam05922; PPC, bacterial pre-peptidase Cterminal domain, pfam04151; P_proprotein, proprotein convertase P-domain, pfam01483; PKD, PKD I domain, cd00146 (or smart00089). The deseasin MCP-01 sequence is indicated by an asterisk. Detailed information about the sequences used for tree construction is shown in Supplementary Table S1.

\section{Structural analysis of mature MCP-01}

The mature deseasin MCP-01 enzyme was purified from the culture of Pseudoalteromonas sp. SM9913 and its purity was monitored by capillary electrophoresis (Supplementary Fig. S1). Its N-terminal sequence and molecular mass were analysed. The $\mathrm{N}$-terminal sequence of the mature enzyme was SATNDP, showing that the signal peptide and the subtilisin_N domain are cleaved when the enzyme is secreted outside the cell. The molecular mass of the mature enzyme measured by MALDI-TOF MS was $65.84 \mathrm{kDa}$ (Supplementary Fig. S2). Based on its molecular mass and $\mathrm{N}$-terminal sequence, it was predicted that mature MCP-01 contained 639 amino acid residues from S1 to E639, which indicates that the $\mathrm{C}$-terminal sequence is also cleaved off at a predicted site between E639 and L640 during the maturation of the enzyme. Therefore, the mature deseasin MCP-01 is a multidomain protein composed of a catalytic region, a linker, a P_proprotein domain and a $\mathrm{PKD}$ domain. The P_proprotein domain, also termed P domain, is a region of eukaryotic subtilisin-like proprotein convertases located immediately downstream of the catalytic domain (Gluschankof \& Fuller, 1994). The PKD domain, which was first identified in human polycystin-1 (The International Polycystic Kidney Disease Consortium, 1995), has been found in bacterial collagenases (Matsushita et al., 1999), proteases (Oda et al., 1996; Miyamoto et al., 2002), cellulases (Ahsan et al., 1996) and chitinases (Perrakis et al., 1994; Orikoshi et al., 2005).

We tried to construct a homologous model of deseasin MCP-01. Because the subtilase structures in the database are all monodomains, a homologous model of intact deseasin MCP-01 could not be constructed. However, based on the structure of the thermostable protease from Bacillus strain Ak.1 (Smith et al., 1999), the catalytic domain of deseasin MCP-01 was modelled by CPHmodels 2.0 Server (http://www.cbs.dtu.dk/services/CPHmodels/) (Lund et al., 2002) (Fig. 2a). All the typical structural characteristics of S8 subtilases could be found in the model of the catalytic domain of MCP-01, such as the sevenstranded parallel beta-sheets and the catalytic triad of Asp, His and Ser. However, two inserts between the Asp and His residues of the catalytic triad of MCP-01 were found when 

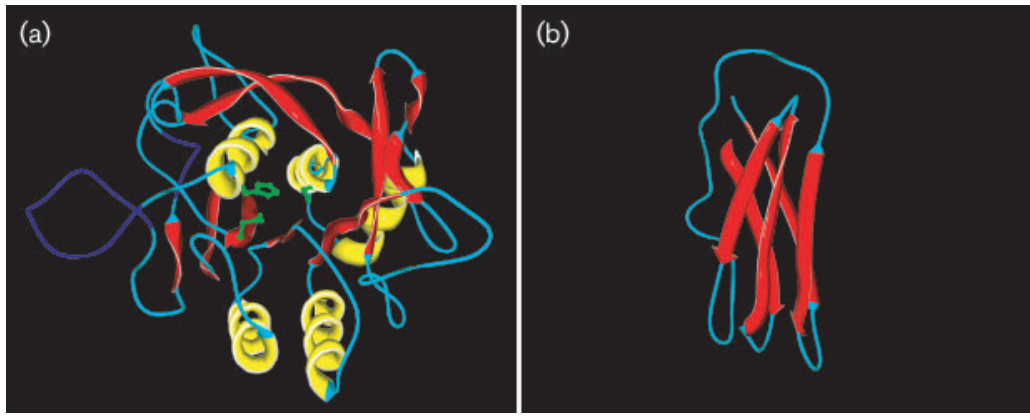

Fig. 2. Ribbon representation of the catalytic domain (a) and the PKD domain (b) of MCP01. Homology modelling was conducted at CPHmodels 2.0 Server (http://www.cbs.dtu. $\mathrm{dk} /$ services/CPHmodels/) (Lund et al., 2002) with templates 1DBI.pdb for the catalytic domain and 1R64.pdb for the PKD domain. The secondary structural elements are represented in yellow (helices), red (sheets) and cyan (random coils), and the catalytic triad in green. Two segments of the loops shown in blue are the inserts in MCP-01 compared to other subfamily S8A subtilases. The figure was prepared with Swiss-PdbViewer version 3.7 (Guex \& Peitsch, 1997). compared to that of some typical subtilases, such as subtilisin Carlsberg, thermitase, protease $\mathrm{K}$ and Kexin (Fig. 3). The positions of the inserts in the model of the catalytic domain of MCP-01 are shown in Fig. 2(a). They are in two loops at the surface of the catalytic domain and make the corresponding loops longer. In addition, a homologous model of the PKD domain of MCP-01 was also constructed with 1R64.pdb as the template (Fig. 2b). Like the structures of other PKD domains (Miyamoto et al., 2002), it has a beta-sandwich fold containing five parallel beta-sheets.

\section{Substrate-specificity analysis of MCP-01}

The mature enzyme of MCP-01 purified from the culture of Pseudoalteromonas sp. SM9913 was used to hydrolyse proteins and synthetic peptides. MCP-01 could hydrolyse all tested proteins: casein, BSA and gelatin. Synthetic peptides are usually used to evaluate the substrate specificity of a protease. MCP-01 had much higher specific activity towards AAPL than $N$-succinyl-Ala-Ala-Pro-Phep-nitroanilide (AAPF) (Table 1), while other subtilases usually have higher specific activity towards AAPF than AAPL, e.g. subtilisin Carlsberg (Table 1), Ak.1 (Toogood et al., 2000) and SapSh (Kulakova et al., 1999). Moreover, unexpectedly, the highest specific activity towards a synthetic peptide for MCP-01 was with FVR. In contrast, subtilisin Carlsberg, the type example of subfamily S8A, had no activity towards FVR (Table 1). In addition, MCP-01 had no activity towards synthetic peptides $N$-succinyl-Ala-Ala-Val-p-nitroanilide (AAV), $N$-succinylGly-Gly-Gly-p-nitroanilide (GGG) and $N$-succinyl-GlyGly-Phe- $p$-nitroanilide (GGF), while subtilisin Carlsberg had activity towards them (Table 1 ). These results showed that the substrate specificity of MCP-01 was different from that of subtilisin Carlsberg. The results also showed that subtilisin Carlsberg had much higher activity than MCP-01 towards the same substrates, such as casein, AAPF and AAPL, showing that the catalytic efficiency of MCP-01 is, as a whole, much lower than that of subtilisin Carlsberg, which may result from differences in structure or the purity of the enzyme preparations.

\section{Structural characteristics of deseasin MCP-01 for cold adaptation}

The novelty of MCP-01 is reflected in its low sequence identity to previously characterized subtilases. The model template automatically chosen by CPHmodels 2.0 Server was the thermostable protease from thermophilic Bacillus strain Ak.1. The catalytic domain of MCP-01 has reasonably high identity (33\%) to this thermostable protease (Smith et al., 1999). A comparison of the amino acid sequences and structure parameters of the catalytic domain of MCP-01 and protease Ak.1 is shown in Table 2. Many structural characteristics of the catalytic domain of deseasin MCP-01 likely to reflect cold adaptation were evident. The catalytic domain of MCP-01 had a higher content of acidic amino acids and a lower content of basic amino acids, which increases the potential for interaction between the protein and solvent and gives a lower pI. Another characteristic of the catalytic domain of MCP-01 is a lower hydrophobic amino acid content than that of the thermostable protease Ak.1. Moreover, the aliphatic index of the catalytic domain of MCP-01 calculated from molar ratios and the relative volumes of the Ala, Val, Ile and Leu residues by the method of Ikai (1980) is lower than that of protease Ak.1. A low grand average of hydropathicity (GRAVY) index and aliphatic index are common traits of psychrophilic enzymes. These primary structural characteristics reflect the structural cold adaptation of the catalytic domain of MCP-01.

\section{Biochemical properties of deseasin MCP-01}

Several catalytic properties of MCP-01 towards casein have been described in our previous report and they primarily show that MCP-01 is a cold-adapted protease (Chen et al., 2003a). In order to further test for cold-adapted characters, its catalytic properties were measured and compared with 


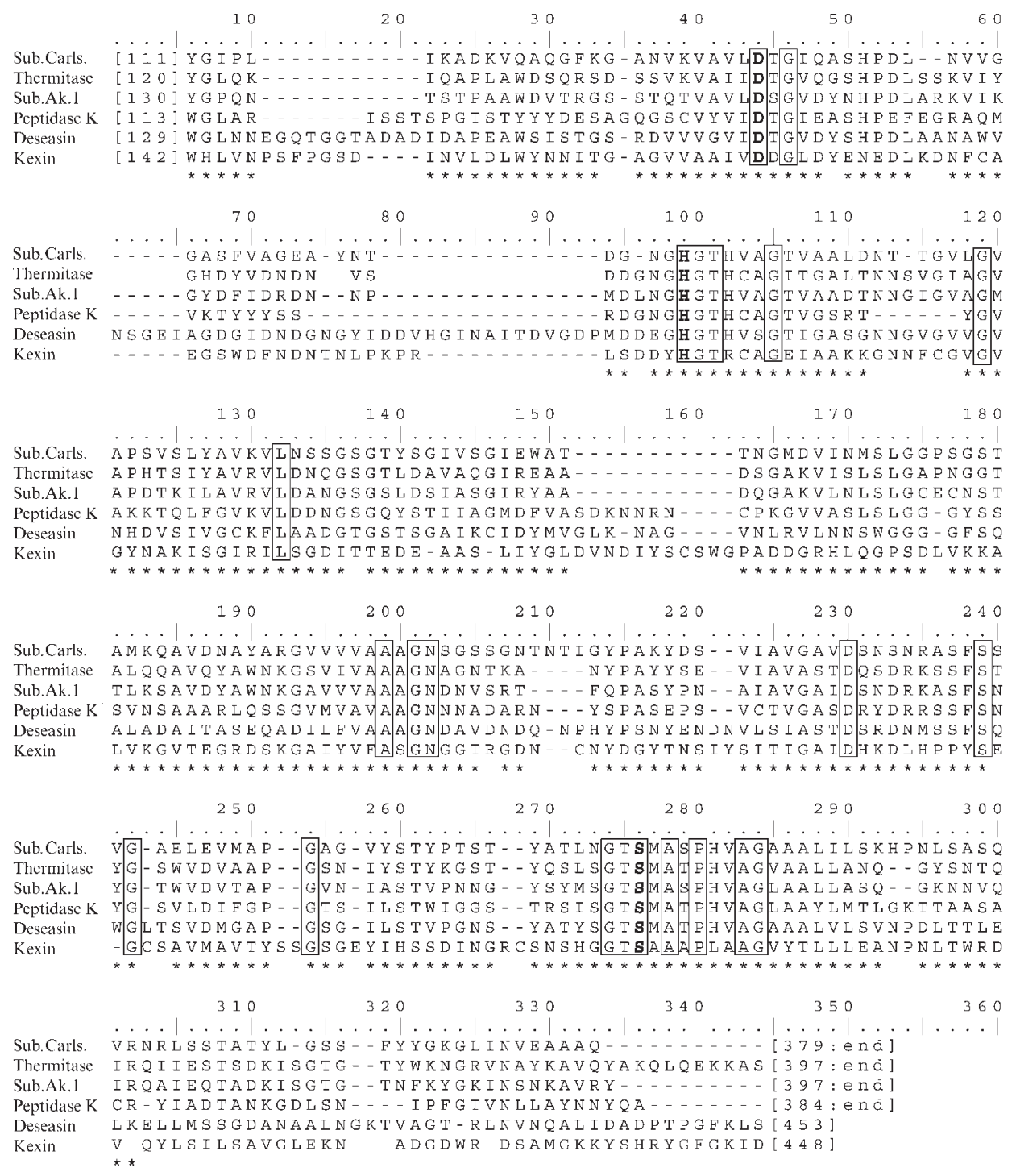

Fig. 3. Sequence alignment of MCP-01 and subtilases in family S8. Asp, His, and Ser of the catalytic triad are shown in bold type. The positions conserved in all six sequences are boxed. For each sequence, the beginning and end positions in the original sequence (the corresponding gi number is shown below) are indicated in brackets. Sequence positions included in the phylogenetic analysis are indicated by an asterisk in the bottom row. Abbreviations: Sub.Carls., subtilisin Carlsberg, Bacillus licheniformis, gi135016; Thermitase, thermitase, Bacillus cereus E33L, gi52143098; Sub.Ak.1, subtilisin Ak.1, Bacillus sp. PD498, gi1890101; Peptidase K, peptidase K, Tritirachium album, gi131077; Deseasin, deseasin MCP-01, Pseudoalteromonas sp. SM9913, gi110083909; Kexin, kexin, Saccharomyces cerevisiae, gi125350.

those of the mesophilic subtilisin Carlsberg (Table 3; Supplementary Figs S3-S6). The results showed that the $k_{\text {cat }}$ of subtilisin Carlsberg was much higher than that of MCP-01 at the same temperatures, indicating that MCP-01 has a lower turnover efficiency towards AAPL than subtilisin Carlsberg. MCP-01 had an optimal temperature of $25{ }^{\circ} \mathrm{C}$ with AAPL as substrate, while subtilisin Carlsberg had an optimal temperature of $55{ }^{\circ} \mathrm{C}$ with the same substrate. Moreover, the activity of MCP-01 at $0{ }^{\circ} \mathrm{C}$ was $45.2 \%$ of its maximal activity, while subtilisin Carlsberg at
$0{ }^{\circ} \mathrm{C}$ had only $4.8 \%$ of its maximal activity. Therefore, relative to their respective maximal activity, MCP-01 has higher catalytic efficiency than subtilisin Carlsberg at $0{ }^{\circ} \mathrm{C}$. The specificity constant $k_{\text {cat }} / K_{\mathrm{m}}$ is generally a better indication of catalytic efficiency than $k_{\text {cat }}$ alone (Feller, 2003). MCP-01 had a higher value of $k_{\text {cat }} / K_{\mathrm{m}}$ at $5{ }^{\circ} \mathrm{C}$ than at $20{ }^{\circ} \mathrm{C}$, further showing its higher catalytic efficiency at low temperature. In addition, cold-adapted enzymes usually have lower Arrhenius energy of activation $\left(E_{\mathrm{a}}\right)$, enthalpy $\left(\Delta H^{\#}\right)$ and entropy $\left(\Delta S^{\#}\right)$ in catalytic reactions 
Table 1. Comparison of specific activities of MCP-01 with that of subtilisin Carlsberg towards various synthetic substrates

The activities of MCP-01 were measured at $\mathrm{pH} 9.0$ (optimum) and 25 ${ }^{\circ} \mathrm{C}$ for synthetic substrates, and $\mathrm{pH} 9.0$ and $40{ }^{\circ} \mathrm{C}$ for casein. For subtilisin Carlsberg, all measurements were at $\mathrm{pH} 10,55^{\circ} \mathrm{C}$. One unit of activity $(\mathrm{U})$ corresponds to one micromole of the reaction product released from substrate for one minute at optimal temperature and $\mathrm{pH}$. The data on MCP-01 and subtilisin Carlsberg shown in Table 1 are the mean of three experimental repeats with $\mathrm{SD} \leqslant 5 \%$.

\begin{tabular}{|c|c|c|c|}
\hline Substrate & $\begin{array}{l}\text { Specific activity } \\
\text { of MCP-01 } \\
\left(\mathrm{U} \mathrm{mg}^{-1}\right)\end{array}$ & $\begin{array}{c}\text { Specific activity } \\
\text { of Ak. } \mathbf{1}^{\star} \\
\left(\mathbf{U} \mathbf{~ m g}^{-1}\right)\end{array}$ & $\begin{array}{c}\text { Specific activity } \\
\text { of subtilisin } \\
\text { Carlsberg } \\
\left(\mathrm{U} \mathrm{mg}^{-1}\right)\end{array}$ \\
\hline Casein & 0.68 & - & 15.6 \\
\hline FVR & 342.9 & - & 0 \\
\hline AAPF & 17.8 & 313.79 & 59040 \\
\hline AAPL & 232.4 & 103 & 51498 \\
\hline $\mathrm{AAA}^{*}$ & 2.94 & 16.89 & 9812 \\
\hline AAV & 0 & - & 5636 \\
\hline GGG & 0 & - & 12223 \\
\hline GGF & 0 & - & 6715 \\
\hline
\end{tabular}

${ }^{\star}$ The data of specific activity of subtilisin Ak.1 in Table 1 are cited from Toogood et al. (2000).

$\dagger$ AAA, $N$-succinyl-Ala-Ala-Ala- $p$-nitroanilide.

than their mesophilic analogues, because of their more flexible structure (Feller, 2003; Siddiqui \& Cavicchioli, 2006). MCP-01 showed lower $E_{\mathrm{a}}, \Delta H^{\#}$ and $\Delta S^{\#}$ during catalysis than mesophilic subtilisin Carlsberg (Table 3). These catalytic properties show that MCP-01 is a coldadapted enzyme. In addition, MCP-01 is an acidic protein with a pI of about 3.5 (Supplementary Fig. S7), showing that there is a lot of negative charge on the molecular surface. This is a common characteristic of psychrophilic enzymes (Siddiqui \& Cavicchioli, 2006; Feller, 2003).

\section{DISCUSSION}

Pseudoalteromonas sp. SM9913, isolated from a deep-sea sediment, is a cold-adapted bacterium with an optimum temperature for growth of $15{ }^{\circ} \mathrm{C}$. Deseasin MCP-01 is the main protease secreted by this strain (Chen et al., 2003a). Sequence analysis showed that the gene mcp01 encodes a multidomain subtilase precursor with seven regions. Database searches identified 12 other predicted subtilases with similar domain architecture. Considering that most of these proteases are from deep-sea bacteria, we term these novel subtilases deseasins. In the phylogenetic tree, all deseasin-like sequences form a group with a high bootstrap support of $99 \%$ and a long evolutionary distance from other subtilase sequences in subfamily S8A. This indicates that deseasins (MCP-01 and the MCP-01-like sequences) represent a novel type of subtilase. The 12 MCP-01-like subtilases were all derived from genomic sequences, and their catalytic characteristics are as yet unknown. MCP-01 from Pseudoalteromonas sp. SM9913 is the type example of a deseasin, since it is the first one to be purified and characterized.

Most mature subtilases in subfamily S8A are monodomain enzymes (Rawlings \& Barrett, 2004). The mature enzyme of deseasin MCP-01 is a structurally novel multidomain subtilase containing a catalytic domain, a linker, a P_proprotein domain and a PKD domain. Only one other subtilase with a PKD domain has been reported before (Miyamoto et al., 2002). It is a chitin-binding protease with a chitin-binding domain at its $\mathrm{C}$ terminus. The structure of this subtilase is obviously different from that of MCP-01 in that its PKD domain is located between its catalytic domain and its chitin-binding domain. Although a PKD domain has been found in many enzymes, its function has rarely been studied. The PKD domain in chitinase A from the marine bacterium Alteromonas sp. strain O-7 has been demonstrated to have binding activity to powdered chitin (Orikoshi et al., 2005). No function for the PKD domain of proteases during catalysis has been shown experimentally. The fact that the PKD domain of MCP-01 still remains in the mature enzyme suggests that it must have a function

Table 2. Properties of MCP-01 and protease Ak.1 determined from a comparison of the deduced amino acid sequences

\begin{tabular}{|c|c|c|c|c|c|c|c|c|c|}
\hline \multirow[t]{2}{*}{ Protease } & \multicolumn{6}{|c|}{ Amino acid frequencies $(\%)^{\star}$} & \multirow[t]{2}{*}{ pI } & \multirow[t]{2}{*}{ GRAVY index } & \multirow{2}{*}{$\begin{array}{c}\text { Aliphatic } \\
\text { index }\end{array}$} \\
\hline & Charged & Acidic & Basic & Polar & Hydrophobic & Aromatic & & & \\
\hline $\mathrm{ME} \dagger$ & 17.52 & 13.61 & 2.35 & 31.14 & 34.41 & 6.42 & 3.77 & -0.155 & 79.20 \\
\hline S8 $\$$ & 18.28 & 13.11 & 3.04 & 29.27 & 35.06 & 5.17 & 3.96 & -0.131 & 82.71 \\
\hline Ak.1§ & 18.93 & 11.89 & 4.84 & 24.67 & 38.33 & 6.61 & 4.36 & -0.046 & 89.47 \\
\hline
\end{tabular}

*The charged amino acids are Arg, Lys, His, Asp and Glu; the acidic amino acids are Asp and Glu; the basic amino acids are Lys and Arg; the polar amino acids are Asn, Cys, Glu, Ser and Thr; the hydrophobic amino acids are Ala, Ile, Leu, Phe, Trp and Val; and the aromatic amino acids are Phe, Trp and Tyr.

$\dagger \mathrm{ME}$, mature enzyme of MCP-01.

$\$$ S8, catalytic domain (S8) of MCP-01.

$\S$ Ak.1, Bacillus Ak.1 protease. 


\section{Table 3. Comparison of properties of deseasin MCP-01 and subtilisin Carlsberg}

The catalytic properties of MCP-01 and subtilisin Carlsberg were measured with AAPL as substrate. The activation energy $\left(E_{\mathrm{a}}\right)$ was determined from an Arrhenius plot shown in Supplementary Fig. S4. $\Delta G^{\#}, \Delta H^{\#}$ and $\Delta S^{\#}$ were calculated by the formula shown in Methods. $K_{\mathrm{m}}$ values of MCP-01 and subtilisin Carlsberg with AAPL as substrate at 5 and $20{ }^{\circ} \mathrm{C}$ were determined by the Lineweaver-Burk plots shown in Supplementary Figs S5 and S6, respectively. The data shown in Table 3 are the mean of three experimental repeats with SD $\leqslant 5 \%$.

\begin{tabular}{|lcc|}
\hline Property & MCP-01 & Subtilisin Carlsberg \\
\hline Optimal pH & 9.0 & 10.0 \\
Optimal temperature $\left({ }^{\circ} \mathrm{C}\right)$ & 25 & 55 \\
Activity at $0{ }^{\circ} \mathrm{C}($ percentage of maximum activity) & 45.2 & 4.8 \\
Kinetic constants $\left(5-20{ }^{\circ} \mathrm{C}\right)$ & & \\
$K_{\mathrm{m}}(\mathrm{mM})$ & $0.45-0.75$ & $0.28-0.26$ \\
$k_{\mathrm{cat}}\left(\mathrm{s}^{-1}\right)$ & $579-815$ & $2177-6600$ \\
$k_{\mathrm{cat}} / K_{\mathrm{m}}\left(\mathrm{mM} \mathrm{s}^{-1}\right)$ & $1287-1087$ & $7775-25385$ \\
Thermodynamic activation constants & & \\
$E_{\mathrm{a}}\left(\mathrm{kJ} \mathrm{mol}^{-1}\right)$ & 25.7 & 42.9 \\
$\Delta G^{\#}\left(\mathrm{~kJ} \mathrm{~mol}^{-1}\right)$ & 53.5 & 50.3 \\
$\Delta H^{\#}\left(\mathrm{~kJ} \mathrm{~mol}^{-1}\right)$ & 23.4 & 40.6 \\
$\Delta S^{\#}\left(\mathrm{~J} \mathrm{~mol}^{-1} \mathrm{~K}^{-1}\right)$ & -108.5 & -34.6 \\
\hline
\end{tabular}

during MCP-01 catalysis. We are now studying the function of the PKD domain of MCP-01 during catalysis.

Most subtilases in subfamily S8A are non-specific peptidases with a preference for an aromatic amino acid residue at the P1 position (Siezen \& Leunissen, 1997; Grøn et al., 1992; Kulakova et al., 1999). The substrate specificity of deseasin MCP-01 to AAPF and AAPL differed from that of three other subtilisins, Carlsberg (this study), Ak.1 (Toogood et al., 2000) and SapSh (Kulakova et al., 1999). The most striking difference, however, was the activity of deseasin MCP-01 towards the synthetic substrate FVR. Subtilases in subfamily S8A have not been widely tested with synthetic substrates with basic residues at the P1 position. However, the lack of activity of subtilisin Carlsberg towards FVR suggests that cleavage after basic residues may be a distinctive aspect of deseasins that warrants further investigation.

Cold-adapted enzymes have a high flexibility that results in their high activity at low temperatures and concomitantly a decreased stability (Siddiqui \& Cavicchioli, 2006; Feller, 2003). Through a model of the structure of the catalytic domain of deseasin MCP-01, many structural characteristics typical of cold-adapted proteins could be seen. Besides the primary structural characteristics shown in Table 2, there are two inserts in the catalytic domain of MCP-01 when its sequence and structure are compared with that of mesophilic subtilases. Since, when compared with mesophilic and thermophilic homologues, coldadapted enzymes usually have more, or longer, loops connecting alpha-helices and beta-sheets, and longer surface loops increase the possible amplitude of the movement between secondary structures and may decrease enzyme stability (Siddiqui \& Cavicchioli, 2006), the two inserts in the catalytic domain of MCP-01, which make the corresponding loops longer, probably increase the local flexibility around the active site of MCP-01; this needs to be verified by further investigation. Furthermore, comparisons of catalytic properties with those of subtilisin Carlsberg provided strong evidence of low-temperature adaptation in deseasin MCP-01. The optimum temperature for deseasin MCP-01 was low. This is a typical feature of cold-adapted (as opposed to cold-active) enzymes and reflects their greater flexibility, making them prone to unfolding and inactivation at only moderate temperatures (Feller, 2003). In addition, the percentage of maximal activity at $0{ }^{\circ} \mathrm{C}$ for deseasin $\mathrm{MCP}-01$ was much greater $(45.2 \%)$ than that of subtilisin Carlsberg $(4.8 \%)$. The $k_{\text {cat }} /$ $K_{\mathrm{m}}$ value of MCP-01 at $5{ }^{\circ} \mathrm{C}$ was higher than that at $20{ }^{\circ} \mathrm{C}$. These data show that deseasin MCP-01 has higher catalytic efficiency at low temperature. Although cold-adapted enzymes frequently have higher catalytic efficiency than their mesophilic counterparts, this is not a universal feature. Our data show that subtilisin Carlsberg had higher efficiency, despite the cold adaptation of deseasin MCP-01. Despite the fact that subtilisin Carlsberg and deseasin MCP-01 both belong to subfamily S8A, their structures are obviously different, which may explain this difference in catalytic efficiency. Alternatively, subtilisin Carlsberg, purified by crystallization, may have much higher purity than deseasin MCP-01, which was purified by gel-filtration chromatography. Besides a low optimum temperature and high $k_{\text {cat }} / K_{\mathrm{m}}$ at low temperature, deseasin MCP-01 shows lower $E_{\mathrm{a}}, \Delta H^{\#}$ and $\Delta S^{\#}$ during catalysis than subtilisin Carlsberg. The deep-sea environment in which strain Pseudoalteromonas sp. SM9913 is presumed to exist has a temperature permanently around $4{ }^{\circ} \mathrm{C}$. To enable the strain to utilize the surrounding protein efficiently for its survival, deseasin MCP-01, the main protease secreted by this strain, must have a high catalytic efficiency in the cold environment. 
The results of this study show that MCP-01 is structurally and kinetically adapted to low temperatures.

\section{ACKNOWLEDGEMENTS}

This work was supported by the Hi-Tech Research and Development Program of China (2006AA09Z414), the National Natural Science Foundation of China (Z2004D02), the Natural Science Foundation of Shandong Province, China (Z2004D02), and the Foundation for Young Excellent Scientists in Shandong Province (2006BS02002).

\section{REFERENCES}

Ahsan, M. M., Kimura, T., Karita, S., Sakka, K. \& Ohmiya, K. (1996). Cloning, DNA sequencing and expression of the gene encoding Clostridium thermocellum cellulose CelJ, the largest catalytic component of the cellulosome. J Bacteriol 178, 5732-5740.

Bendtsen, J. D., Nielsen, H., Von Heijne, G. \& Brunak, S. (2004). Improved prediction of signal peptides: SignalP 3.0. J Mol Biol 340, 783-795.

Bradford, M. M. (1976). A rapid and sensitive method for the quantitation of microgram quantities of protein utilizing the principle of protein-dye binding. Anal Biochem 72, 248-254.

Chen, X.-L., Sun, C.-Y., Zhang, Y.-Z. \& Gao, P.-J. (2002). Effects of different buffers on the thermostability and autolysis of a coldadapted protease MCP-01. J Protein Chem 21, 523-527.

Chen, X.-L., Zhang, Y.-Z., Gao, P.-J. \& Luan, X.-W. (2003a). Two different proteases produced by a deep-sea psychrotrophic strain Pseudoaltermonas sp. SM9913. Marine Biol 143, 989-993.

Chen, X.-L., Sun, C.-Y., Zhang, Y.-Z. \& Gao, P.-J. (2003b). Rapid monitoring of autolysis process of proteases by capillary electrophoresis. Biotechnol Lett 25, 1763-1767.

Dayhoff, M. O., Schwartz, R. M. \& Orcutt, B. C. (1978). A model of evolutionary change in proteins. In Atlas of Protein Sequence and Structure, pp. 345-358. Edited by M. O. Dayhoff. Washington, DC: National Biomedical Research Foundation.

Feller, G. (2003). Molecular adaptation to cold in psychrophilic enzymes. Cell Mol Life Sci 60, 648-662.

Georlette, D., Blaise, V., Collins, T., D’Amico, S., Gratia, E., Hoyoux, A., Marx, J.-C., Sonan, G., Feller, G. \& Gerday, C. (2004). Some like it cold: biocatalysis at low temperatures. FEMS Microbiol Rev 28, 25-42.

Gluschankof, P. \& Fuller, R. S. (1994). A C-terminal domain conserved in precursor processing proteases is required for intramolecular $\mathrm{N}$ terminal mutation of pro-Kex2 protease. EMBO J 13, 2280-2288.

Grøn, H., Meldal, M. \& Breddam, K. (1992). Extensive comparison of the substrate preferences of two subtilisins as determined with peptide substrates which are based on the principle of intramolecular quenching. Biochemistry 31, 6011-6018.

Guex, N. \& Peitsch, M. C. (1997). SwISS-MODEL and the SwissPdbViewer: an environment for comparative protein modeling. Electrophoresis 18, 2714-2723.

Hall, T. A. (1999). BioEdit: a user-friendly biological sequence alignment editor and analysis program for Windows 95/98/NT. Nucleic Acids Symp Ser 41, 95-98.

He, H., Chen, X., Li, J., Zhang, Y. \& Gao, P. (2004). Taste improvement of refrigerated meat treated with cold-adapted protease. Food Chem 84, 307-311.

Huang, L. \& Forsberg, C. W. (1987). Isolation of a cellodextrinase from Bacteroides succinogenes. Appl Environ Microbiol 53, 1034-1041.
Ikai, A. (1980). Thermostability and aliphatic index of globular proteins. J Biochem (Tokyo) 88, 1895-1898.

Juncker, A. S., Willenbrock, H., Heijne, G., Nielsen, H., Brunak, S. \& Krogh, A. (2003). Prediction of lipoprotein signal peptides in Gramnegative bacteria. Protein Sci 12, 1652-1662.

Kulakova, L., Galkin, A., Kurihara, T., Yoshimura, T. \& Esaki, N. (1999). Cold-active serine alkaline protease from the psychrotrophic bacterium Shewanella strain Ac10: gene cloning and enzyme purification and characterization. Appl Environ Microbiol 65, 611-617.

Kumar, S., Tamura, K. \& Nei, M. (2004). MEGA3: integrated software for molecular evolutionary genetics analysis and sequence alignment. Brief Bioinform 5, 150-163.

Laemmli, U. K. (1970). Cleavage of structural proteins during the assembly of the head of bacteriophage T4. Nature 227, 680-685.

Liu, Y. G. \& Whittier, R. F. (1995). Thermal asymmetric interlaced PCR: automatable amplification and sequencing of insert end fragments from P1 and YAC clones for chromosome walking. Genomics 25, 674-681.

Lund, O., Nielsen, M., Lundegaard, C. \& Worning, P. (2002). CPHmodels 2.0: X3M a computer program to extract 3D models. Abstract A102 at the CASP5 Conference, Fifth Community-Wide Experiment on the Critical Assessment of Techniques for Protein Structure Prediction, Pacific Grove, CA, December 2002.

Marchler-Bauer, A., Anderson, J. B., Cherukuri, P. F., DeWeeseScott, C., Geer, L. Y., Gwadz, M., He, S., Hurwitz, D. I., Jackson, J. D. \& other authors (2005). CDD: a conserved domain database for protein classification. Nucleic Acids Res 33, D192-D196.

Matsushita, O., Jung, C.-M., Katayama, S., Minami, J., Takahashi, Y. \& Okabe, A. (1999). Gene duplication and multiplicity of collagenases in Clostridium histolyticum. J Bacteriol 181, 923-933.

Miyamoto, K., Nukui, E., Itoh, H., Sato, T., Kobayashi, T., Imada, C., Watanabe, E., Inamori, Y. \& Tsujibo, H. (2002). Molecular analysis of the gene encoding a novel chitin-binding protease from Alteromonas sp. strain O-7 and its role in the chitinolytic system. J Bacteriol 184, $1865-1872$.

Murray, M. G. \& Thompson, W. F. (1980). Rapid isolation of high molecular weight plant DNA. Nucleic Acids Res 8, 4321-4325.

Oda, K., Ito, M., Uchida, K., Shibano, Y., Fukuhara, K. \& Takahashi, S. (1996). Cloning and expression of an isovaleryl pepstatin-insensitive carboxyl proteinase gene from Xanthomonas sp. T-22. J Biochem (Tokyo) 120, 564-572.

Orikoshi, H., Nakayama, S., Hanato, C., Miyamoto, K. \& Tsujibo, H. (2005). Role of the N-terminal polycystic kidney disease domain in chitin degradation by chitinase A from a marine bacterium, Alteromonas sp. strain O-7. J Appl Microbiol 99, 551-557.

Peek, K., Veitch, D. P., Prescott, M., Daniel, R. M., Maclver, B. \& Bergquist, P. L. (1993). Some characteristics of a proteinase from a thermophilic Bacillus sp. expressed in Escherichia coli: comparison with the native enzyme and its processing in E. coli and in vitro. Appl Environ Microbiol 59, 1168-1175.

Perrakis, A., Tews, I., Dauter, Z., Oppenheim, A. B., Chet, I., Wilson, K. S. \& Vorgias, C. E. (1994). Crystal structure of a bacterial chitinase at $2.3 \AA$ resolution. Structure 2, 1169-1180.

Rawlings, N. D. \& Barrett, A. J. (2004). Introduction: serine peptides and their clans. In Handbook of Proteolytic Enzymes, 2nd edn, pp. 1425-1427. Edited by A. J. Barrett, N. D. Rawlings \& J. F. Woessner. London: Elsevier.

Rawlings, N. D., Morton, F. R. \& Barrett, A. J. (2006). MEROPS: the peptidase database. Nucleic Acids Res 34, D270-D272.

Siddiqui, K. S. \& Cavicchioli, R. (2006). Cold-adapted enzymes. Annu Rev Biochem 75, 403-433. 
Siezen, R. J. \& Leunissen, J. A. M. (1997). Subtilases: the superfamily of subtilisin-like proteases. Protein Sci 6, 501-523.

Smith, C. A., Toogood, H. S., Baker, H. M., Daniel, R. M. \& Baker, E. N. (1999). Calcium-mediated thermostability in the subtilisin superfamily: the crystal structure of Bacillus Ak.1 protease at $1.8 \AA$ resolution. J Mol Biol 294, 1027-1040.

The International Polycystic Kidney Disease Consortium (1995). Polycystic kidney disease: the complete structure of the PKD1 gene and its protein. Cell 81, 289-298.
Thompson, J. D., Gibson, T. J., Plewniak, F., Jeanmougin, F. \& Higgins, D. G. (1997). The CLUSTALX windows interface: flexible strategies for multiple sequence alignment aided by quality analysis tools. Nucleic Acids Res 25, 4876-4882.

Toogood, H. S., Smith, C. A., Baker, E. N. \& Daniel, R. M. (2000). Purification and characterization of Ak.1 protease, a thermostable subtilisin with a disulphide bond in the substrate-binding cleft. Biochem J 350, 321-328.

Edited by: A. Holmes 